NASA/TM-2003-212547

\title{
Optical Measurements for Intelligent Aerospace Propulsion
}

\author{
Carolyn R. Mercer
}

Glenn Research Center, Cleveland, Ohio 
Since its founding, NASA has been dedicated to the advancement of aeronautics and space science. The NASA Scientific and Technical Information (STI) Program Office plays a key part in helping NASA maintain this important role.

The NASA STI Program Office is operated by Langley Research Center, the Lead Center for NASA's scientific and technical information. The NASA STI Program Office provides access to the NASA STI Database, the largest collection of aeronautical and space science STI in the world. The Program Office is also NASA's institutional mechanism for disseminating the results of its research and development activities. These results are published by NASA in the NASA STI Report Series, which includes the following report types:

- $\quad$ TECHNICAL PUBLICATION. Reports of completed research or a major significant phase of research that present the results of NASA programs and include extensive data or theoretical analysis. Includes compilations of significant scientific and technical data and information deemed to be of continuing reference value. NASA's counterpart of peerreviewed formal professional papers but has less stringent limitations on manuscript length and extent of graphic presentations.

- TECHNICAL MEMORANDUM. Scientific and technical findings that are preliminary or of specialized interest, e.g., quick release reports, working papers, and bibliographies that contain minimal annotation. Does not contain extensive analysis.

- CONTRACTOR REPORT. Scientific and technical findings by NASA-sponsored contractors and grantees.
- CONFERENCE PUBLICATION. Collected papers from scientific and technical conferences, symposia, seminars, or other meetings sponsored or cosponsored by NASA.

- SPECIAL PUBLICATION. Scientific, technical, or historical information from NASA programs, projects, and missions, often concerned with subjects having substantial public interest.

- TECHNICAL TRANSLATION. Englishlanguage translations of foreign scientific and technical material pertinent to NASA's mission.

Specialized services that complement the STI Program Office's diverse offerings include creating custom thesauri, building customized databases, organizing and publishing research results ... even providing videos.

For more information about the NASA STI Program Office, see the following:

- Access the NASA STI Program Home Page at http://www.sti.nasa.gov

- E-mail your question via the Internet to help@sti.nasa.gov

- Fax your question to the NASA Access Help Desk at 301-621-0134

- Telephone the NASA Access Help Desk at 301-621-0390

- Write to:

NASA Access Help Desk

NASA Center for AeroSpace Information 7121 Standard Drive

Hanover, MD 21076 
NASA/TM-2003-212547

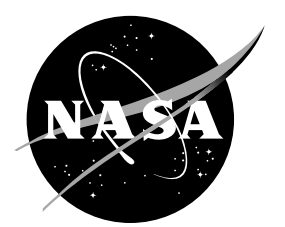

\section{Optical Measurements for Intelligent Aerospace Propulsion}

\section{Carolyn R. Mercer}

Glenn Research Center, Cleveland, Ohio

Prepared for the

2003 Annual Meeting

sponsored by the International Society for Optical Engineering

San Diego, California, August 3-8, 2003

National Aeronautics and

Space Administration

Glenn Research Center 
Available from

NASA Center for Aerospace Information 7121 Standard Drive

Hanover, MD 21076
National Technical Information Service 5285 Port Royal Road Springfield, VA 22100

Available electronically at http://gltrs.grc.nasa.gov 


\title{
Optical Measurements for Intelligent Aerospace Propulsion
}

\author{
Carolyn R. Mercer \\ National Aeronautics and Space Administration \\ Glenn Research Center \\ Cleveland, Ohio 44135
}

\begin{abstract}
There is growing interest in applying "intelligent" technologies to aerospace propulsion systems to reap expected benefits in cost, performance, and environmental compliance. Cost benefits span the engine life cycle from development, operations, and maintenance. Performance gains are anticipated in reduced fuel consumption, increased thrust-to-weight ratios, and operability. Environmental benefits include generating fewer pollutants and less noise. Critical enabling technologies to realize these potential benefits include sensors, actuators, logic, electronics, materials and structures. For propulsion applications, the challenge is to increase the robustness of these technologies so that they can withstand harsh temperatures, vibrations, and grime while providing extremely reliable performance. This paper addresses the role that optical metrology is playing in providing solutions to these challenges. Optics for ground-based testing (development cycle), flight sensing (operations), and inspection (maintenance) are described. Opportunities for future work are presented.
\end{abstract}

\section{INTRODUCTION}

Improvements in air transportation have long been led by improvements in aerospace propulsion systems. Air frames have evolved to reap the benefits of available propulsion technology. From the piston-cylinders of the Wright Brothers to the jet engines of World War II, the combined cycle engines of the SR-71, and supersonic turbojet of the Concorde, and from expendable to reusable rockets for space transportation, advances in propulsion have afforded large benefits to aerospace transportation systems. While historically these advances have led primarily to increased speed, advances are now sought in reduced environmental impact and increased affordability.

Improvements in environmental compatibility include reducing the amounts of pollutants and noise generated by aircraft engines, particularly around airports. Specific pollutants currently targeted for reduction include soot, oxides of nitrogen, and carbon dioxide, and international standards exist for their regulation. Oxides of sulfur, micro-particulates, and even water vapor may soon be regulated as unwanted pollution sources. Noise requirements are increasingly stringent as airport travel increases, with European airports leading the way in maximum allowable levels. Economic pressures are demanding greatly improved engine reliability, particularly since airlines have moved from purchasing engines outright and instead buy "power by the hour," or leased, maintenance-contracted engines. Space transportation systems are not yet subject to noise and emission regulations, but are under increasing pressure to operate highly costeffectively and safely.

To achieve these ever-tightening requirements, "intelligent" technologies are being applied to aerospace propulsion systems. These technologies include sensors, actuators, logic, electronics, materials and structures. For propulsion applications, the challenge is to increase the robustness of these technologies so that they can withstand harsh temperatures, vibrations, and grime while providing extremely reliable performance. There are three primary areas for inserting intelligent technologies into engine applications: during design and test of new engines, during flight, and back on the ground for engine maintenance (figure 1). Sensors are being developed for each of these areas. ${ }^{1}$ Optics can play an important role in each of these areas, although widespread acceptance and application of optics is currently concentrated in the design and test phase. Examples of current and future use of optics in these areas are presented below, followed by summary comments. 

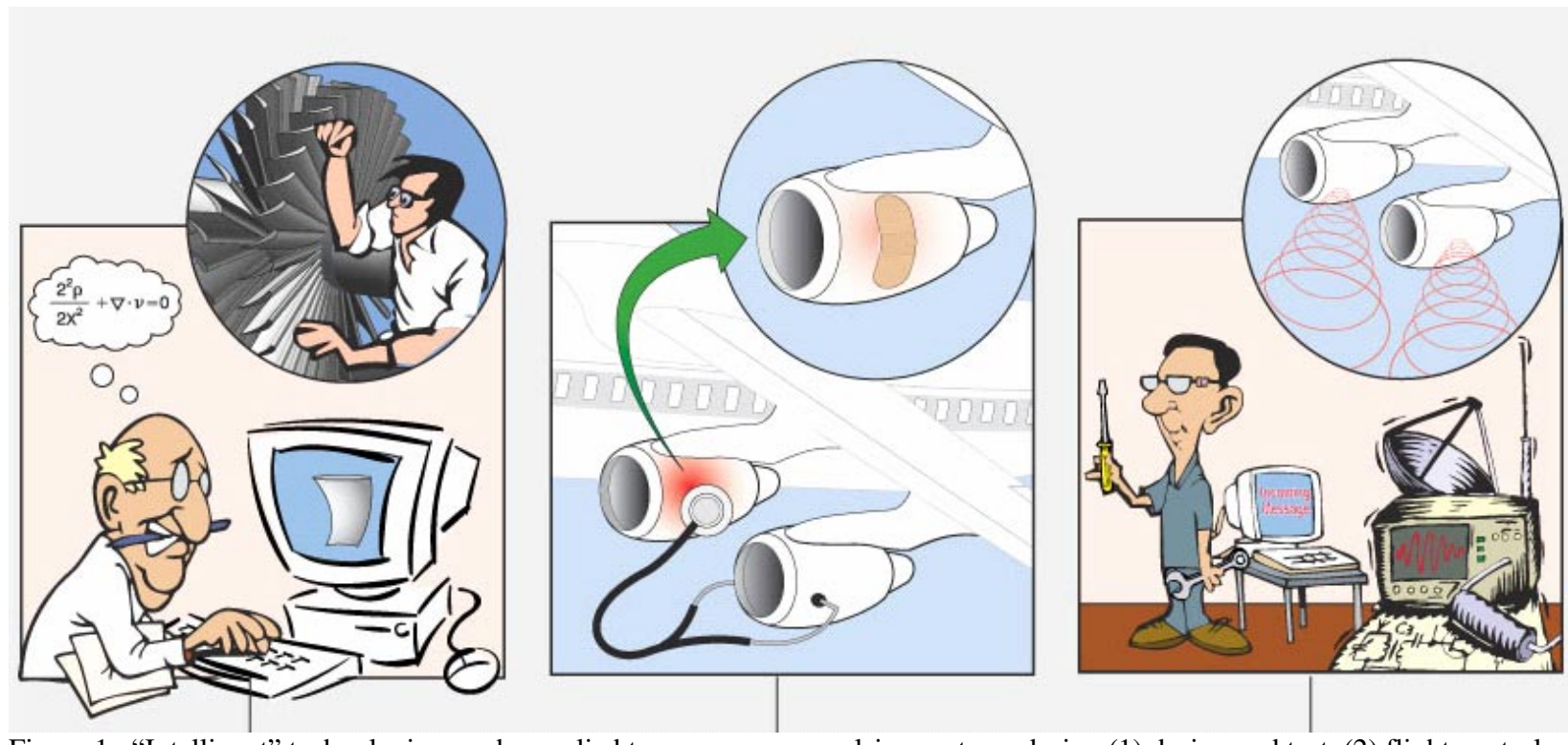

Figure 1. "Intelligent" technologies can be applied to aerospace propulsion systems during (1) design and test, (2) flight control, and (3) ground-based maintenance.

\section{DESIGN AND TEST}

Optical instrumentation has been used extensively to measure the entire range of parameters of interest to engine designers for both aeronautics- and space-based systems. ${ }^{2}$

Commonly used gas-path measurements include velocimetry, spectroscopy, and visualization techniques to study air flows throughout engine components, from subsonic to hypersonic applications. Rayleigh scattering measurements are also used in particular applications, and interferometry, although less common because of its indirect measurement of parameters of interest, has its place as well. Laser Doppler velocimetry measures statistical flow properties at discrete points, particle imaging velocimetry is used for instantaneous, high-spatial resolution planar measurements (figure 2), Doppler global velocimetry for planar measurements over large areas, and molecular tagging velocimetry for nonseeded measurements. Optical techniques including planar laser induced fluorescence, planar Mie-regime scattering (figure 3), laser diode absorption, and coherent anti-stokes Raman spectroscopy are used to study flows in combustors for advanced high-pressure aircraft engines and supersonic combustors for reusable space transportation engine concepts. Schlieren systems are routinely used for wind tunnel testing (figure 4), and recently have been used during flight tests, showing shock formations and turbulent mixing. Rayleigh scattering is used to measure gas density, temperature, and species concentration, primarily in un-enclosed, non-seeded flows (figure 5). High-sampling-rate dynamic measurements for statistical flow properties are made at a point, or areas can be imaged to measure mean flows. Turbulent mixing for aircraft engine nozzles or rocket fuel/oxidizer mixing are common applications. Interferometry provides very precise refractive-index measurements, which can in turn be related to gas density, temperature, or composition. Common-path interferometry provides a robust way to measure gas density distributions in test cell environments. Tomography is then used to extract planar information from the line-of-sight-integrated interferometric data.

Surface measurements include luminescent phosphors, or temperature sensitive paints, to provide detailed temperature maps of surfaces ranging from ice-covered inlets to combustion liners. Similar technology is being used to measure surface pressures and heat flux, each covering entire surfaces by recording a single pair of digital camera images (figure 6). Holographic interferometry is in use to determine the structural properties of engine components such as blades, disks, blisks, and shrouds, including automated, high speed, damage detection using neural net processing (figure 7). 


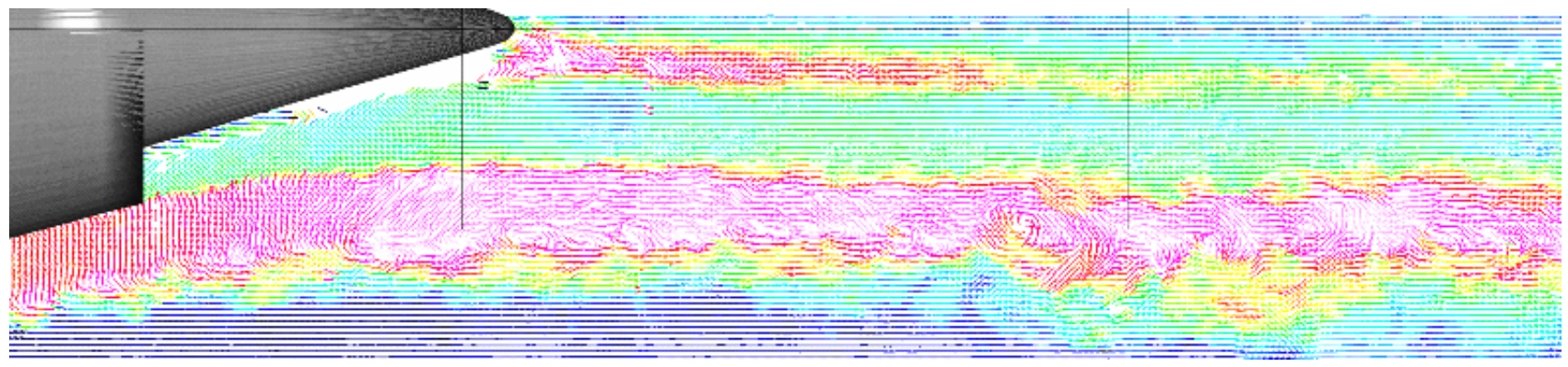

Figure 2. Particle Imaging Velocimetry data. Pseudo-instantaneous flowfield shows engine nozzle core/fan mixing. Image courtesy of M.P. Wernet, NASA GRC. ${ }^{3}$

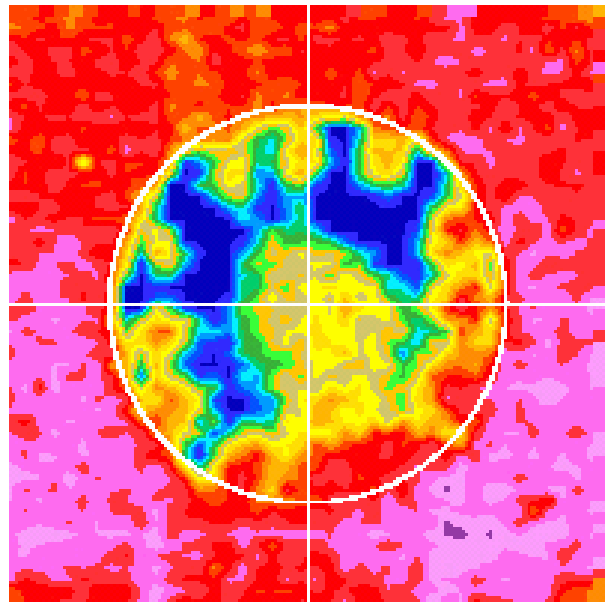

Figure 3. Planar Mie regime scattering image showing cross-sectional fuel distribution in a high pressure jet-fueled combustor injector. Image courtesy of R.J. Locke, QSS Group, Inc. ${ }^{2}$

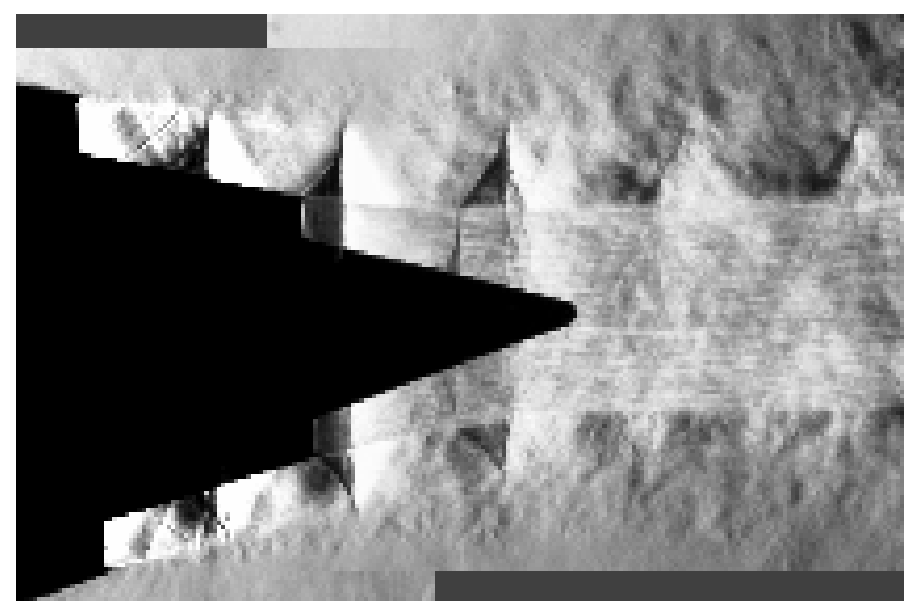

Figure 4. Schlieren image showing shock wave formation in an annular engine nozzle. Image courtesy of J.D. Lekki, NASA GRC.

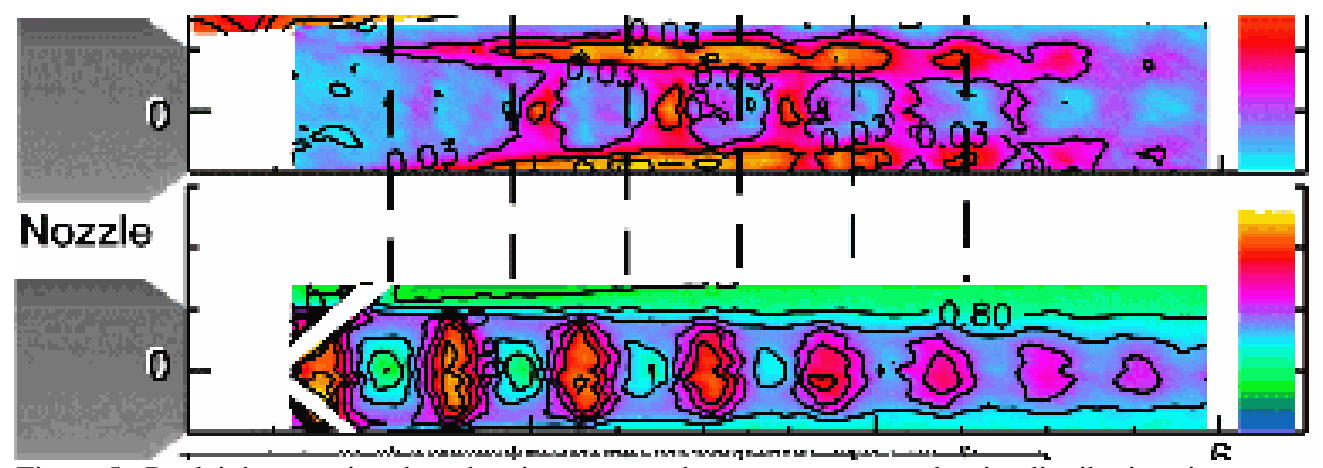

Figure 5. Rayleigh scattering data showing mean and root-mean-square density distributions in a supersonic nozzle. Image courtesy of R.G. Seasholtz, NASA GRC. ${ }^{4}$

Optical pyrometry is used to measure temperature distributions in the hot section environments and to characterize the performance of new materials at elevated temperatures. Optically interrogated liquid crystal tracers are used to measure gas temperature distributions. Surface shear strains are measured by oil film interferometry and liquid crystal "paints" to validate codes render visible design changes on flows. 


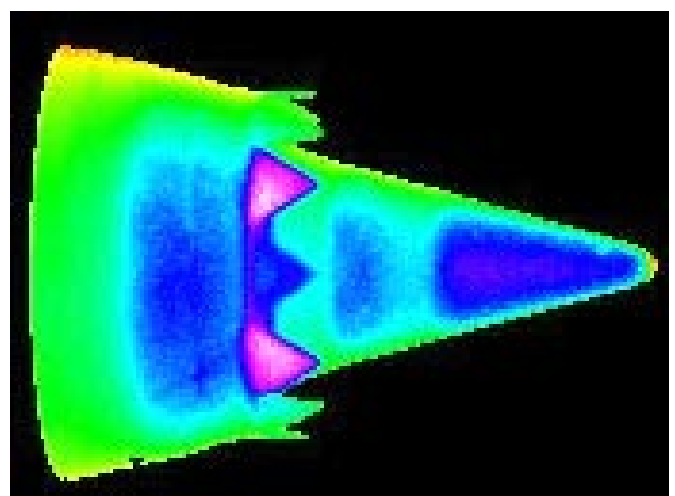

Figure 6. Luminescent paint data showing surface pressure distribution in a tabbed-fan engine nozzle. Image courtesy of T.J. Bencic, NASA GRC.

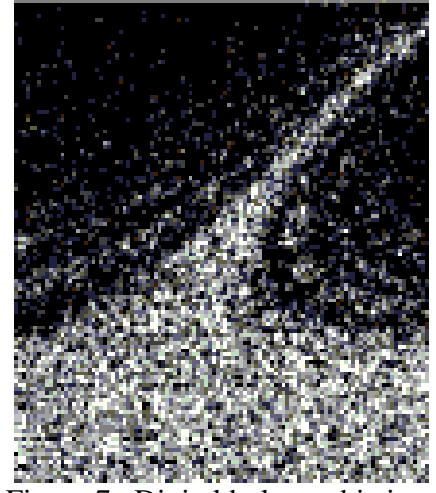

Figure 7. Digital holographic interferogram showing characteristic vibration mode of a vibrating engine fan blade. Image courtesy of A.J. Decker, NASA GRC. ${ }^{5}$

In aggregate, these optical instrumentation systems have dramatically affected the design and test phase for aerospace engines. The ability to acquire millions of data points with a single camera shot, each point representing a quantified value of velocity or temperature or pressure with high accuracy has not only validated countless computer models, permitting faster derivative designs, but often has also changed designers' fundamental understanding of mechanisms under study. "A picture is worth a thousand data points" is a variant on the old adage that serves the engineering community well.

\section{FLIGHT SYSTEMS}

"Intelligent" propulsion in-flight concepts include active component control, autonomous operations, and fault-tolerant controls. ${ }^{6}$ Active component control includes actively controlling the various propulsion subsystems to reduce design margins that are routinely included in passive systems. These design margins generally lead to heavier components than might be possible if "worst-case" scenario design could be replaced by adaptive designs optimized for particular flight conditions. For instance, fan by-pass ratios could be decreased for take-off and opened back up for optimum cruise conditions. Tip clearances for compressors and turbines could be sensed and continuously minimized rather than operating too large to accommodate "pinch points." Micro-jet flow control can be used to increase turbine or compressor blade loading leading to fewer stages, leading in-turn to reduced manufacturing costs and weight, fuel burn, emissions. Active combustion control can lead to more uniform mixing for reduced emissions, as well as increased stability for lean-burn designs hence reduced emissions. ${ }^{8} \quad$ Compressor flow control can provide increased blade loading, permitting fewer stage and hence lighter engines that are less expensive to manufacture. Active control of compressor instabilities can also reduce weight, and therefore emissions through reduced fuel consumption. ${ }^{9}$ And active noise control and noise cancellation can be used to reduce noise near airports without paying the penalty during cruise. ${ }^{10}$ Each of these systems requires sensors, actuators, communication, and power.

Autonomous propulsion flight control is desirable to minimize pilot workload and reduce pilot errors, and to enable reliable long-duration flights for uninhabited air vehicles. Again, sensing, actuation, communication and power are required. Fault-tolerant controls can provide safe operation during engine malfunctions, including loss of power and component failure. Control concepts range from algorithms based on sensing simple parameters such as changes in temperature and pressure, to those incorporating direct measurements of failing components. Again, sensors, actuators, communications and power are critical.

Propulsion flight sensors, actuators, communications and power can be as simple as existing thermocouples and pressure sensors, throttle control, and wires for communications and power. These combinations are used in-flight today, and provide the reliable operation needed for economic engine operation. Advanced concepts exist to provide more detailed information about the engine environment and component health than is currently available using a small number of point sensors. 
The primary advantages of optical sensors are their ability to sense at a distance (non-contact), potential for very precise measurements (sub-wavelength resolution), their inherent ability to interrogate large areas and volumes instantaneously (parallel processing), and their ability to encode multiple measurands on a single signal (multiplexing). The primary disadvantages are their reliance on line-of-sight measurements and susceptibility to fouling. Another obstacle to the use of optical systems is the same as for any other new technology: economic inertia. The current infrastructure is set up to handle existing wires, cables, and sensors. Retraining and retooling is expensive, and a reliability database is not established.

Nonetheless, optical sensors have the potential to buy their way into aerospace engines in a variety of applications. Optical pyrometry is standard to monitor hot section component temperatures. Blackbody radiation sensors and sapphire-fiber Fabry-Perot interferometers have been made commercially available for exhaust gas temperature sensing. Fiber optic pressure sensors have been embedded into spark plugs for internal combustion engines. Optical shaft-angle encoders have been developed, and fly-by-light control architectures have been designed and prototyped. The Space Shuttle is currently using emission spectroscopy to monitor the main engine exhaust plume for unwanted metals as an indicator of engine degradation. Fiber optic Bragg sensors are being developed as embedded structural health monitors for fuel tanks and engine shrouds, where their ability to measure localized strains and temperatures offer significant advantages over point accelerometers. Triboluminescent materials hold intriguing possibilities as light weight damage sensors embedded directly into composites.

Laser diode-based spectrometers can be used to monitor combustion by-products to assess combustion uniformity for active combustion control. Spatially resolved optical pyrometers can directly measure temperature uniformity, to suppress NOx-producing "hot spots." Chemiluminsence-based NOx gas analyzers are commercially available for ground testing; converting these devices to flight sensors would provide direct measurement of emissions production during operation. Fluorescence-based chemical sensors can measure leaks as well as emissions. Diode-based sensors have been developed to measure soot temperature, soot volume fraction and fuel concentration. Optical pressure sensors can be used to monitor combustion instabilities.

Optical clearance sensors can be used to measure the distance between rotating blades and their surrounding shrouds during flight. Real-time clearance monitoring coupled with dynamic actuators can reduce the specific fuel consumption by a few percent. Optical vibration sensors can indicate the structural health of blades. Optical flow sensors can be used to monitor actively controlled micro-flows to increase blade loading and reduce noise. Micro-fabricated optomechanical pressure sensors can detect boundary layer transitions, as can embedded fiber optic strain sensors. Interferometric surface shape measurements can provide feedback for morphing structures.

Diode lasers, super-luminescent light emitting diodes are available to provide optical power for these sensors, in robust, lightweight packages that weren't available a decade ago. Micro-fabricated white light sources are also being developed to power sensors based on white-light interferometry or broadband imaging. Combustion radiation itself can serve as a source of optical power for sensors.

Novel optically-based actuators have been proposed. Laser based ignition has been used for rockets, and proposed for internal combustion engines to improve start system reliability, combustion efficiency, and lower-energy ignition for lean-burning combustors. Laser-based heating of shape memory alloys has been proposed; these can be used to actuate flow "trip strips," move flaps, or modulate micro-jets. Optically actuated surface corrugations of photorefractive materials has also been demonstrated and can be used for surface flow control.

Finally, optical fibers are well positioned to contribute substantially to the controls architecture of aerospace vehicles, including their engine systems. As the number of sensors and temporal demands of active controllers increases, data bandwidth requirements will correspondingly increase. Fiber optic communications lines can fill this need in the air just as they have on the ground, and with the added important advantage of lower weight compared to copper wire and immunity to electromagnetic interference, the leading obstacle to the adoption of wireless communications on aircraft. (figure 9). 


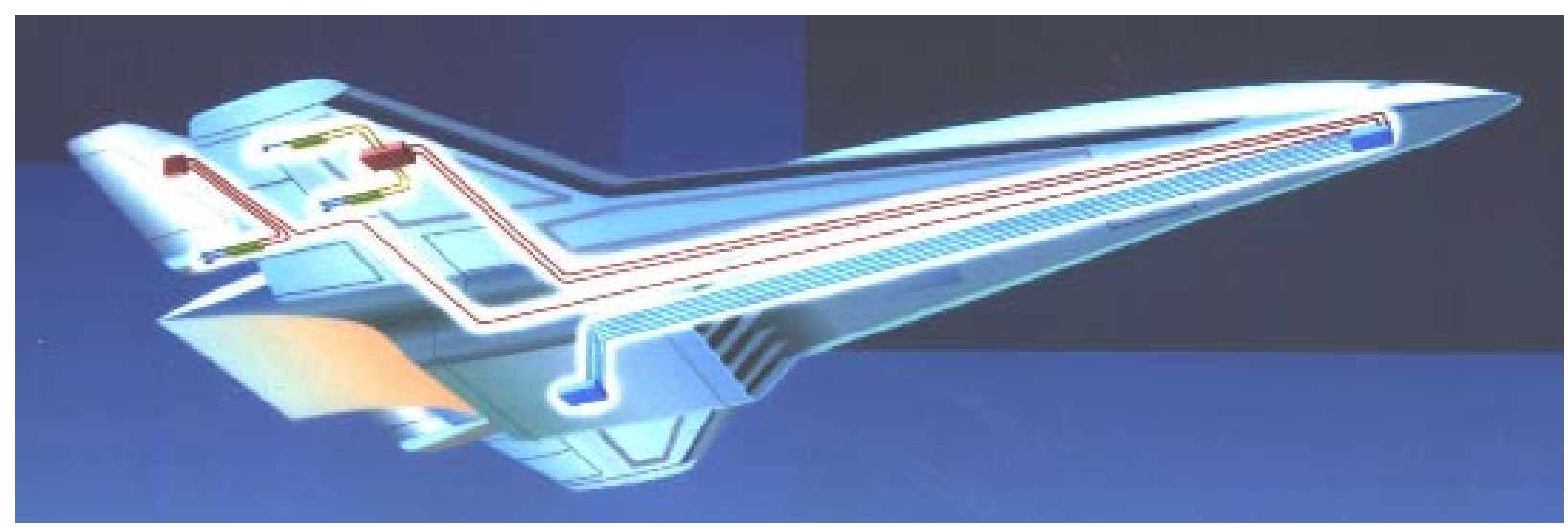

Figure 9. Fly-by-light architecture can increase data bandwidth while eliminating hazards caused by electromagnetic interference.

\section{MAINTENANCE}

The final broad category for aerospace propulsion measurements is maintenance. Ground-based inspections are currently labor-intensive and performed on a conservative hours-flown based schedule rather than automated and needbased. The primary optical sensor in use today is the ubiquitous borescope. This visual inspection method is becoming more automated with the advent of digital cameras and image processing. Fiber optic Bragg sensors are being used to measure LOx tank levels (figure 10), and an optical plume anomaly detection system is used to detect defects in the Space Shuttle main engine (figure 11). Embedded fiber Bragg gratings have been demonstrated for use a process control sensors for resin transfer molded components, with the beneficial result of having instrumented structural elements for in-flight health monitoring and ground-based inspection. Interferometry has been developed to measure surface shapes, with the ability to detect cooling tube displacements in the Space Shuttle main engine and potentially warping of blade surfaces for turbomachinery. The health of surface treatments such as thermal barrier coatings can be assessed spectroscopically or by embedded temperature sensitive paints. Lubrication systems can be monitored to detect debris and component degradation. Embedded sensors for flight health management can be interrogated on the ground, or flight data can be telemetered to the ground to give advance warning to the ground crew. Micro-devices equipped with miniature cameras can crawl through the engine in search of cracks, debonds, and spalling.

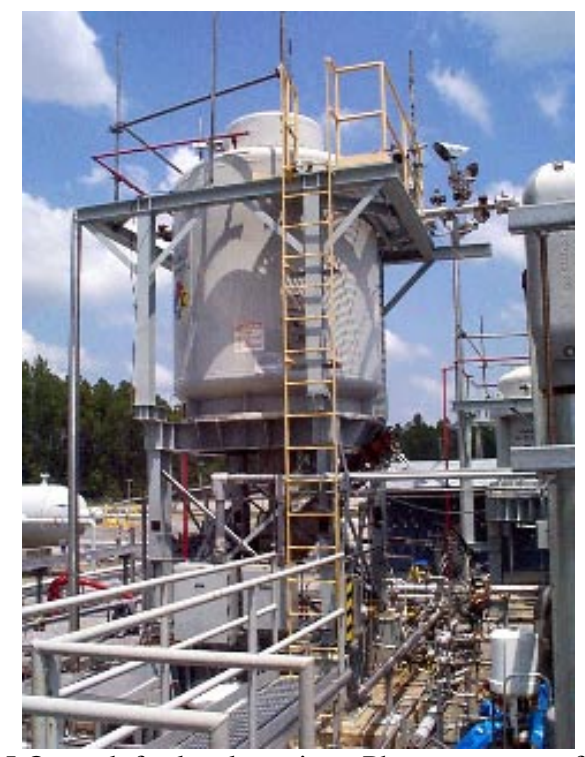

Figure 10. Instrumented LOx tank for level sensing. Photo courtesy of F. Figueroa, NASA SSC. 


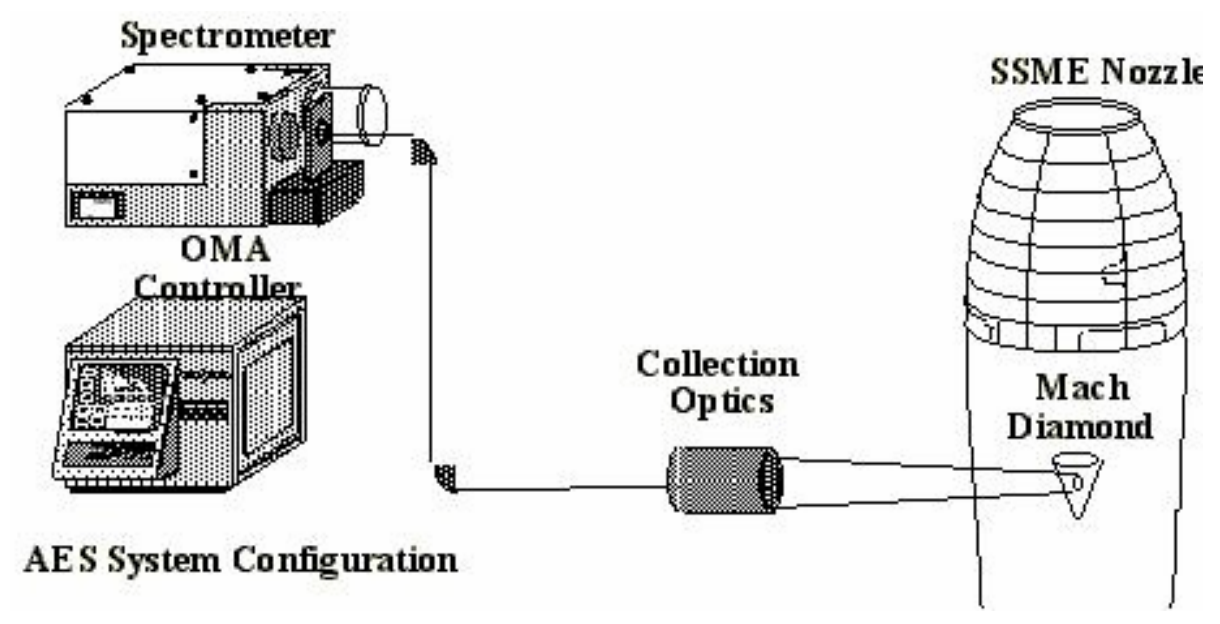

Figure 11. Optical plume anomaly detection system spectroscopically interrogates rocket exhaust plume to detect metals. Image courtesy of F. Figueroa, NASA SSC. ${ }^{1}$

\section{SUMMARY AND FUTURE DIRECTIONS}

"Intelligent" technologies are being applied to aerospace propulsion systems to reap benefits in cost, performance, and environmental compliance. Optical instrumentation has revolutionized the design and test phase of aerospace engine development, and optics-based sensors, communication systems, and actuators can have similar impact during the flight and maintenance phases of engine applications.

Future directions include the intelligent merging of the vast amount of data obtained from computational models and experimental testing for engine design. This data will serve as the basis for model-based propulsion control, coupled with flight sensor data to determine real-time deviations from nominal performance. This knowledge can be used for active accommodation of dynamic conditions such as environmental changes and engine degradation over time, leading to improved performance, reduced cost, and increased safety.

\section{REFERENCES}

1. F. Figueroa, C.R. Mercer, "Advancing sensor technology for aerospace propulsion," ASME International Mechanical Engineering Congress and Exposition, New Orleans, LA, IMECE2002-33179, November 2002.

2. C. Mercer, editor, Optical Metrology for Fluids, Combustion and Solids, Kluwer Academic Publishers, Boston, MA, 2003.

3. M.P. Wernet, J. Bridges, “Application of DPIV to Enhanced Mixing Heated Nozzle Flows” AIAA-2002-00691, 40th Aerospace Sciences Meeting, Reno, NV, January 2002.

4. J. Panda, R.G. Seasholtz, "Measurement of shock structure and shock-vortex interaction in underexpanded jets using Rayleigh scattering," Physics of Fluids v. 11 no. 12, pp. 3761-3777, December 1999.

5. A.J. Decker, "Neural-net processing of characteristic patterns," Y. Bar-Cohen, ed., Automation, Miniature Robotics and Sensors for Nondestructive Evaluation and Testing, Vol. 4, Topics On Nondestructive Evaluation, B.B. Djordjevic and H.D. Reis, The American Society for Nondestructive Testing, Inc., Columbus, OH (2000).

6. S. Garg, "Propulsion Controls and Health Management Research at NASA Glenn Research Center," NASA/TM2002-211590, July 2002.

7. S.B. Lattime, B.M. Steinetz, "Turbine engine clearance control systems: current practices and future directions," AIAA-2002-3790, 38 ${ }^{\text {th }}$ Joint Propulsion Conference, Indianapolis, Indiana, July 7-10, 2002.

8. J.C. DeLaat, K.J. Breisacher, J.R. Saus, D.E. Paxson, “Active combustion control for aircraft gas turbine engines," AIAA-2000-3500, 36 ${ }^{\text {th }}$ Joint Propulsion Conference, Huntsville, AL, July 16-19, 2000.

9. M. Gad-el-Hak, "Flow Control: the future," Journal of Aircraft, v. 38, no. 3, pp. 402-418, 2001.

10. E. Envia, "Fan noise reduction: an overview," International Journal of Aeroacoustics, v.1, no. 1, 2002. 


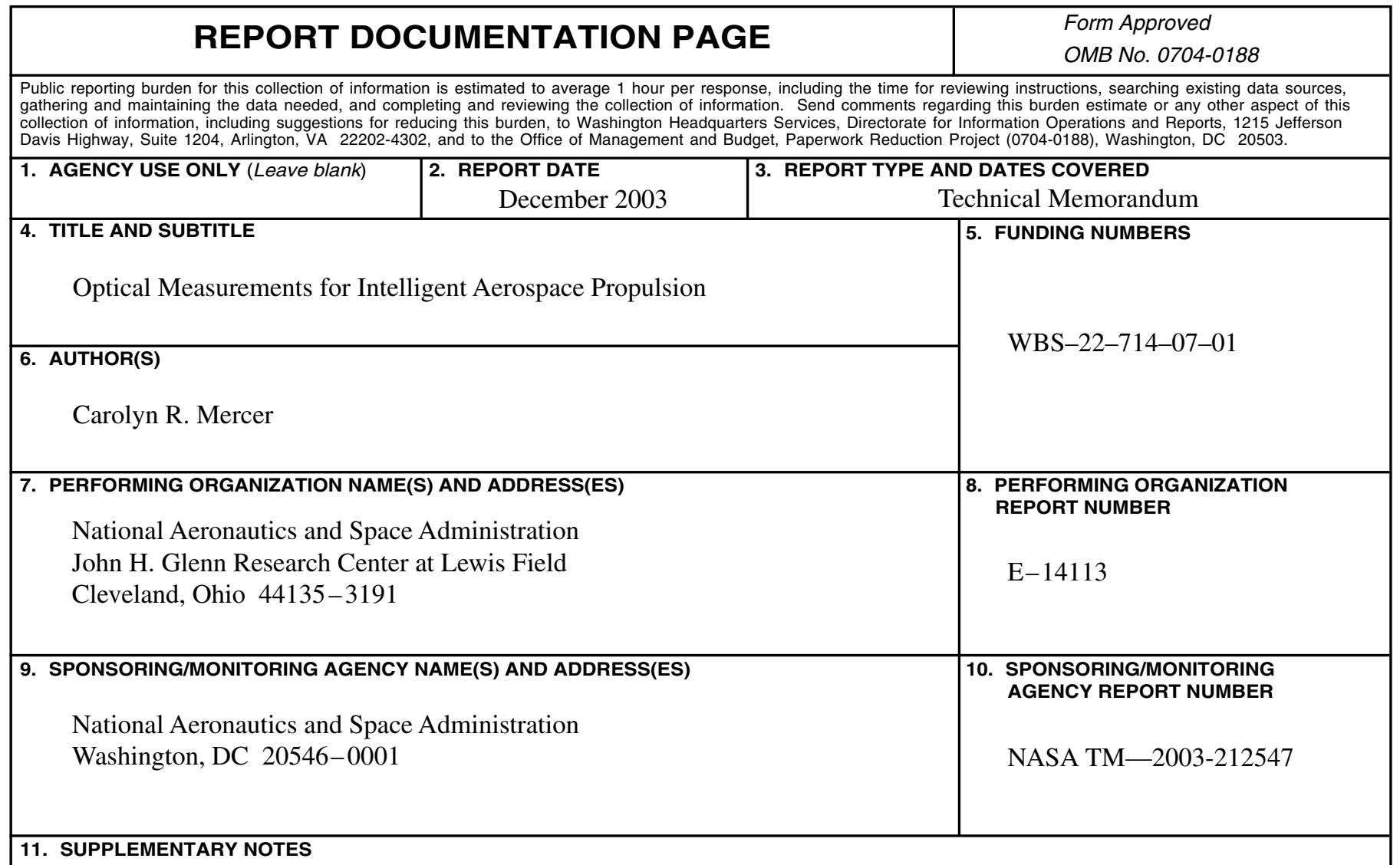

Prepared for the 2003 Annual Meeting sponsored by the International Society for Optical Engineering, San Diego, California, August 3-8, 2003. Responsible person, Carolyn R. Mercer, organization code 2600, 216-433-3411.

\begin{tabular}{l|l|l}
\hline 12a. & DISTRIBUTION/AVAILABILITY STATEMENT & \\
Unclassified - Unlimited & Distribution: Nonstandard & \\
Subject Category: 07 & \\
Available electronically at http://gltrs.grc.nasa.gov & \\
This publication is available from the NASA Center for AeroSpace Information, 301-621-0390. &
\end{tabular}

\section{ABSTRACT (Maximum 200 words)}

There is growing interest in applying "intelligent" technologies to aerospace propulsion systems to reap expected benefits in cost, performance, and environmental compliance. Cost benefits span the engine life cycle from development, operations, and maintenance. Performance gains are anticipated in reduced fuel consumption, increased thrust-toweight ratios, and operability. Environmental benefits include generating fewer pollutants and less noise. Critical enabling technologies to realize these potential benefits include sensors, actuators, logic, electronics, materials, and structures. For propulsion applications, the challenge is to increase the robustness of these technologies so that they can withstand harsh temperatures, vibrations, and grime while providing extremely reliable performance. This paper addresses the role that optical metrology is playing in providing solutions to these challenges. Optics for ground-based testing (development cycle), flight sensing (operations), and inspection (maintenance) are described. Opportunities for future work are presented.

\begin{tabular}{|c|c|c|c|}
\hline \multicolumn{3}{|c|}{$\begin{array}{l}\text { 14. SUBJECT TERMS } \\
\text { Measurement; Propulsion; Aerospace; Optics }\end{array}$} & \begin{tabular}{|l|} 
15. NUMBER OF PAGES \\
13
\end{tabular} \\
\hline NSN 7540-01-280-5500 & & & $\begin{array}{l}\text { andard Form } 298 \text { (Rev. 2-89) } \\
\text { scribed by ANSI Std. Z39-18 } \\
-102\end{array}$ \\
\hline
\end{tabular}

